Session 2320

\title{
The Impact of Advanced Multimedia Technology on the Classroom 2000
}

\author{
Mark R. Rajai, Keith V. Johnson \\ East Tennessee State University
}

\begin{abstract}
This paper studies the latest research on the impact of advanced multimedia technology on the classroom 2000. This paper focuses on one such advanced technology entitled "IPTeam Suite," by Nexprise, Inc, which is starting to become widely used by the industry, but is relatively new to the academia. The application of the IPTeams software in data exchange, information sharing, messaging, and scheduling and documentation and its integration into classroom 2000 are discussed. A joint design course between two universities and an industrial partner, utilizing IPTeam software is also presented. Some of the other new cutting edge educational delivery mode and software such as Asynchronous Learning Networks and ZenPad used in pilot programs in leading universities are also studied.
\end{abstract}

\section{Introduction}

Due to highly competitive working environment, modern businesses have adopted cutting edge technologies as a way to compete in global market place. Because of the perceived benefits of these technologies in transmission of information and the extensive use of them by the modern business world, colleges and universities have begun integrating these technologies into the classroom 2000 environment. ${ }^{1,2,3}$

In this paper we study the impact of new multimedia technology on the classroom 2000 . This paper is organized as follows. In the next section, we present what is a classroom 2000 and how it functions. Next, we discuss some cutting edge new educational delivery mode and software such as Asynchronous Learning Networks and ZenPad used in pilot programs in leading universities in the United States. We then examine one such advanced technology entitled "IPTeams Suite," by Nexprise, Inc, which is starting to become widely used by the industry ${ }^{4}$. This software has been used by industry for team collaboration in an asynchronous mode over the Internet. The software has enabled companies to out-source their work to suppliers and subcontractors and compete more effectively in the global economy. However, this software is relatively new to the academia. We then present a pilot joint course between East Tennessee State University (ETSU), Loyola Marymount University (LMU) in Los Angeles, CA, and their industrial consultant. The IPTeams Suite was used in a new product development course where the students from the two universities have interacted in teams of joint projects. We conclude with some discussions from our own experience with IPTeams Suite software and the pilot project.

\section{Classroom 2000}

The classroom 2000 is a learning environment that would embrace new technologies and allow

"Proceedings of the 2001 American Society for Engineering education Annual Conferences \& Exposition Copyright@ 2001, American Society for Engineering Education” 
instructors and students to maximize the educational process. The classroom 2000 is designed to prepare students for an information based job market ${ }^{5,6,7}$. Gregory Abowd of the Future Computing Environments Research Group at Georgia Technical Institute is developing a classroom environment known as "Classroom 2000," that incorporates many of new technologies in attempt to create a smart classroom. The basic impetus behind Abowds' efforts is to provide the lecturer with up to date technologies to aid in the presentation of the lecture and to eliminate the need for students to take notes during a lecture. The typical classroom hosts hundreds of lectures a year yet is unable to share this information with students. A classroom 2000 shares a complete record of its lectures for future reference. By having the classroom take notes, the student is allowed a greater opportunity to concentrate on the lecture ${ }^{7}$. Other leading universities such as MIT and Stanford University are working on creating virtual classroom and $\operatorname{labs}^{8,9}$. In the next section, we discuss some of these technologies, which have been used in classroom 2000.

\section{Overview of Advanced Multimedia Technologies for the Classroom 2000}

Three cutting edge software and educational delivery mode are discussed in this section.

1.) ZenPad

ZenPad is a Java based client-server system running on an electronic whiteboard to present slides and allow for annotation by teacher. The teacher simply annotates static GIF images with pen. The interface to ZenPad is purposely minimal. The important features of ZenPad not available in commercial software are the production of web-accessible artifacts, namely, GIF images and a time stamped log of important interaction such as penstrokes, with electronic whiteboard. These features enable ZenPad subsequent integration with recorded digital audio or video. ${ }^{7,10}$ ZenPad wad used in Georgia Tech experiment with classroom 2000. ZenPad allows audio and video made during the lecture to be indexed to the notes the instructor records on electronic whiteboard. This information is then compressed using real technologies audio and video compression techniques and posted to the class website. To review a specific topic that took place at a specific time during the lecture, a student need only to click on the notes written on the electronic whiteboard by the instructor at the time he/she was discussing the topic. The audio and video is then played back for the student's review. $6,7,10$

\section{2.) Asynchronous Learning Networks}

Asynchronous learning networks (ALNs) represent one of the most radical applications of instructional technology that supplants a historically valued institutionalized practice -classroom teaching. ALNs entail a different process of identity enhancement. ALNs are defined as distributed learning environments that are "virtual classrooms" involving asynchronous interaction and exchange of information exclusively on-line with no face-to-face interaction or conventional physical classroom arrangements. ${ }^{11,12}$ However, there is some opposition to ALNs based on their historical attachment to the physical classroom environment. ${ }^{12}$

\section{3.) IPTeam Suite}

Nexprise IPTeam Suite provides a virtual environment for a cross-functional product development team to design new products. A cross-functional product development team involves team members from all of the enterprise's functional organizations -- design,

"Proceedings of the 2001 American Society for Engineering education Annual Conferences \& Exposition Copyright (C 2001, American Society for Engineering Education” 
manufacturing, marketing, customer services, and management. The enterprise that is supported by Nexprise includes the supply chain, which is becoming an important part of every enterprise.

The model that IPTeam Suite uses for its environment is a project area. Physical project areas require design notebooks, document configuration control, management plans, and interactions with subcontractors and suppliers. IPTeam Suite supports all of these in a virtual environment and they can be linked together. The design process is an iterative one where choices are made. The design team must be able to record their choices and the information that was used to make that choice. Everyone on the design team must have access to the design information. When a poor choice has been made, the team must be able to backtrack and make a better one. They cannot do this without knowing the other alternatives that the team had. ${ }^{13}$

\section{A Joint Course}

In July, 1999 a grant from Lemelson Foundation was awarded to ETSU and LMU to create an interactive virtual classroom using IPTeam software from Nexprise, Inc. Four groups of students from both universities and our industrial partners participated in this joint project. Our main goal was to introduce virtual interaction into the classroom, because virtual interactions are becoming increasing important as separated teams jointly develop products. ${ }^{4}$ We were motivated by the global outsourcing that is taking place in industry, which requires product to be designed by team members who are not co-located in the same place at the same time.

At LMU and ETSU, there is an emphasis on the classic design process. The major parts of the environment that were used are the document vault, the notebook. Since the class schedule was fixed and there were not suppliers, the workflow and the mail portions of the environment were not used or discussed in the class. The document vault provides the configuration control of documents. Documents can be placed in the vault and then reviewed and revised by all of the members of the team. The iNotebook provides a work area that the team can use to exchange design information synchronously. The iMail and iRoute portions to the environment are used to coordinate and notify team members of new information or documentation that is available. ${ }^{13}$

In the design course, the IPTeam Suite was used by the instructors to coordinate work and assignments. The lecture notes and assignments were made available to the students in at both universities as soon as the class was finished with the classroom document vault. The student teams would then coordinate their work from the assignments in the document vault. Each student team had its own project area with its document vaults, design notebooks and workflow routers. The teams used these areas to develop their product designs. The lecturers could verify that the assignments were being completed in a timely manner by reviewing the work in each of the project areas. The lecturers could also know where the teams were weak and the subjects that would require more emphasis in the classroom.

IPTeam Suite supported the design and development of new products for virtual teams. It provided the communications infrastructure through its use of email, workflow routers and the use of web browsers as the primary user interface. IPTeam Suite was the data retention infrastructure for virtual teams with its virtual project areas, which contained document vaults, virtual notebooks, scheduler and consensus builder. IPTeam Suite used commercial secure

"Proceedings of the 2001 American Society for Engineering education Annual Conferences \& Exposition Copyright (C) 2001, American Society for Engineering Education” 
servers, which worked with corporate firewalls to provide security for the virtual team and its information products. Each virtual team member is authenticated before information is accessed. Since the server can be accessed across the World Wide Web with a web browser, virtual teams can be formed across corporations that are located anywhere in the world.

The virtual teams interacted through their communication and data retention infrastructures. The communication infrastructure supported synchronous work and allowed the teams to coordinate their synchronous work. Synchronous work occurred when team members were working together to create the same new information at the same time. Asynchronous work occurred when the team members worked on different information or work at different times (for the information that the team is producing). The data retention infrastructure allowed the team members to share and modify information across the team. It allowed the team members to resettle information, as it was refined across the life of the product. Both of these factors enabled a virtual team to work and create its products.

\section{Conclusions}

Technology is changing so rapidly, and an increasing number of companies are embracing and implementing new technologies into their workplace, in order to stay competitive in the global market. Colleges and universities have an obligation to embrace these new technologies as well.

In this paper we examined some of these technologies and their perceived benefits and also presented our own personal experience with IPTeam software in the pilot project. We believe by adopting these technologies in the classroom, universities will have the same potential of improving their institutions that businesses have enjoyed through the integration of these technologies into their organizations. The classroom 2000 is a cutting edge learning environment and universities must utilize the capabilities they have to make it a reality. The classroom 2000 learning center is truly our bridge to the future

\section{Acknowledgement}

We wish to express our sincere gratitude to Lemeson Foundation for funding this work.

\section{Bibliography}

[1] Evans, D and Gill, R., 1998, “Teaching The Product Realization Process In The

UndergraduateMechanical/Manufacturing Engineering Curriculum: What Should Students Know?'Manufacturing Education for $21^{\text {st }}$ Century Vol. V

[2] Rozenfeld, H., Aguiar, A., Olivera, C., Omokawa, R., 1998, "Development Of a Concurrent Scenario for Educational Purposes", Manufacturing Education for $21^{\text {st }}$ Century Vol. V

[3] Mendelson, M., Rajai, M., and Bostick, 2000, "Inter-university E-Teams Working on Joint Products”, accepted for $4^{\text {th }}$ annual NCIIA Conference, Washington, D.C., March 2000

[4] Nunamaker, J.F., 1999, “ The Case for Virtual Teaming Systems,"

IT Pro September | October 1999, IEEE

[5] Fogarty, R., 1998, “ The Intelligence-friendly Classroom,” [online] URL:http://www.infomationaccess.com IT Pro September | October 1999, IEEE

"Proceedings of the 2001 American Society for Engineering education Annual Conferences \& Exposition Copyright@ 2001, American Society for Engineering Education" 
[6] Abowd, G., et aL 1996, "Teaching and Learning As Multimedia Authoring: The Classroom 2000 Project, " in the proceedings of Multimedia

[7] Brotherton, and Abowd, G., 1998 "Room Take Note: Room Takes Notes! “, [online], URL: WwW.windows Desktop\roomtakenote.htm

[8] Bishop, M., 1998, "Use Information Technology Creativity, “[online], URL:

http:IInotes.cc.sunsb.edu/Pres/boyes.nsf/wcbform/vi

[9] Stanford University Newsletter on Teaching, "Speaking of Technology, "[online], URL:

http://Lists.stanford.udu

[10] Abowd, G., et aL, 1998 "Classroom 2000: A system for capturing and Accessing Multimedia classroom experiences, “, [online], URL: WWW.Windows\DesktoplCapturec2000.htm

[11] Green, Kenneth C. and Steven W. Gilbert, March/April 1995 "Great Expectations, Content, Communications, Productivity and the Role of Information Technology in Higher Education." CHANGE

[12] Jaffee, D., 1998, "Institutionalized resistance To Asynchronous learning Networks, “ Jan Vol. 2, issue 2

[13] IPteam Suite User Guide, [online] URL: http://demo.nexprise.com

\section{MARK RAJAI}

Mark R. Rajai is an Associate Professor/Director of Manufacturing Engineering Program at East Tennessee State University. He has a Ph.D. in Industrial Engineering and a Master of Engineering in Engineering Management from University of Louisville. He also has a B.S. and M.S. degree in Mechanical Engineering with highest honors from the University of Tennessee. He has more than 13 years of experience in academic and industrial arena. He is the recipient of a number of awards and a member of several national honor societies. He is also member of several professional societies including ASEE. He is author and co-author of several books and peer reviewed journal articles. He is particularly noted for his several inventions that have resulted in national/international media coverage. He is also the founder and currently, president of Safety Edge Corporation; a company that designs and manufactures safety products.

\section{Keith Johnson}

Keith Johnson is an Associate Professor/Interim Chair of Engineering Technology

Department at East Tennessee State University. He has a EdD in Industrial Technology

From North Carolina State university. 